\title{
EFFECT OF GALLERIES ON THE WIND FLOW STRUCTURE AND POLLUTANT TRANSPORT WITHIN STREET CANYONS WITH OR WITHOUT FACADE ROUGHNESS ELEMENTS (BALCONIES)
}

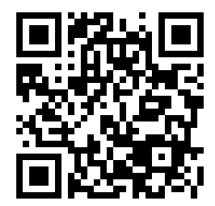

\author{
V. A. Karkoulias ${ }^{*}{ }^{\square}$, P. E. Marazioti ${ }^{2}$, D. P. Georgiou ${ }^{3}$, E. A. Maraziotis ${ }^{1}$ \\ ${ }^{* 1}$ Nuclear Technology Laboratory, Department of Mechanical Engineering and Aeronautics, \\ University of Patras, 26500 Rion-Patras, Greece \\ 2 Department of Mechanical Engineering Educators, School of Pedagogical and Technological \\ Education, Heraclion Attikis,14121, Greece \\ 3 Thermal Engines Laboratory, Department of Mechanical Engineering and Aeronautics, University \\ of Patras, 26500 Rion-Patras, Greece
}

DOI: https://doi.org/10.29121/ijetmr.v7.i12.2020.835

Article Citation: V. A. Karkoulias, P. E. Marazioti, D. P. Georgiou, and E. A. Maraziotis. (2020). EFFECT OF GALLERIES ON THE WIND FLOW STRUCTURE AND POLLUTANT TRANSPORT WITHIN STREET CANYONS WITH OR WITHOUT FACADE ROUGHNESS ELEMENTS (BALCONIES). International Journal of Engineering Technologies and Management Research, 7(12), 4559.

https://doi.org/10.29121/ijetmr.v7 i12.2020.835

Published Date: 28 December 2020

Keywords:

Vertical Distribution Profile

Aerosols Particles

Street Canyon

Galleries

CFD

\section{ABSTRACT}

This paper investigates how the structure of the flow field and the vertical distribution of the pollutant concentration near the wall facades of street canyons are affected by the presence of some elements such as street level galleries. Numerical results are presented for various gallery geometries in combination with facade roughness elements (balconies) for a canyon of an aspect ratio equal to $\mathrm{h} / \mathrm{w}=2.33$. The results were obtained by a Computational Fluid Dynamics (CFD) simulation employing the ANSYS-FLUENT suite that incorporated the k-e turbulent (RNG) model. The simulation generated several flow structures inside the canyon (mainly vortices), whose characteristic properties (e.g. number, strength and size) are discussed in terms of the effect of the galleries on the flow field structure and the roughness generated by the building façade balconies. The results indicate a significant influence on both the flow field structure and the mass concentration distribution of the polluting particles.

\section{INTRODUCTION}

Air pollution in an urban canopy presents an important environmental problem and the study of pollutant dispersion in cities is not an easy matter. The interaction between the overhead atmospheric flow and the urban obstacles, such as buildings, generates a complex flow inside the street canyons that affects the pollutant dispersion.

Air pollution measured as particulate matter (PM) may lead to increased mortality rates (Dockery et al., 1993; Hales et al., 2010). The fine particulate matter, i.e. the particles with a diameter smaller than $2.5 \mathrm{~mm}$ (PM2.5), has been estimated to cause about 3.3 million premature deaths per year worldwide (Lelieveld et al., 2015). The mass of

(C) 2020 The Author(s). This is an open access article distributed under the terms of the Creative Commons Attribution License, which permits unrestricted use, distribution, and reproduction in any medium, provided the original author and source are credited. 
Effect of Galleries on The Wind Flow Structure and Pollutant Transport Within Street Canyons with or Without Facade Roughness Elements (Balconies)

fine particles has been widely monitored in urban areas all over the world (Cheng et al., 2016) and shown to correlate with the incidence of cardiopulmonary diseases (Silva et al., 2013).

The façade roughness elements such as balconies can significantly affect the near-façade airflow patterns (Chand et al., 1998; Montazeri and Blocken, 2013). A better understanding of the impact of façade elements on the near-façade airflow patterns and the pressure distributions on the façade is essential for the accurate evaluation of wind-induced natural ventilation (Gullbrekken et al., 2018; Ramponi et al., 2014), pollutant dispersion (Karkoulias et al., 2019) and convective heat transfer coefficient expressions for isolated buildings (Montazeri and Blocken, 2018).

Wind tunnel experiments and computational fluid dynamics (CFD) simulations have been employed to investigate the impact of building façade geometrical details on the near-façade airflow. The mean velocity and the Air change rate per hour $(\mathrm{ACH})$ in 5-story building configuration $(15 \mathrm{~m}$ building height) with balconies using Steady RANS as a turbulence modeling approach was studied by Ai et al., 2013. Montazeri et al., 2013 investigated the mean velocity distribution in a 22-story building configuration $(78 \mathrm{~m}$ building height) with balconies while Murena and Mele, 2016 studied the particle concentration distribution in 4-story building configuration (18m building height) with balconies using SAS as turbulence modeling approach. Liaguno-Munitxa et al., 2017 studied the mean velocity distribution in a 5-story building configuration with balconies as façade geometrical detail using LES for the modeling of the turbulence. In addition, Reynolds-averaged Navier-Stokes (RANS) simulations have been employed to identify the vertical distribution of the pollutant concentration for a 7-story building configuration (28m height) with balconies (Karkoulias et al., 2019). Additionally, CFD simulations of the wind flow and mean surface pressure for buildings with balconies and comparison of the RANS against the LES were conducted by Zheng et al., 2020. Most of the previous studies focused on buildings with balconies.

The older studies were limited to a single aspect ratio, for which they studied the mean velocity, the mean surface pressure and the distribution of the carbon monoxide as a gaseous pollutant.

Our previous study (Karkoulias et al., 2019), presented results of the vertical distribution profile of aerosol traffic-generated particulate matter with respect to the different floor heights, in typical multistorey buildings forming deep street canyons ( $\mathrm{AR}>2$ ). It demonstrated the following: a) Inside the canyon three vortices were formed. One of them dominated the cross section and rotated in a counterclockwise direction. The smaller vortices rotated in the opposite direction and were forced near the extremities of the canyon. The smaller second vortex appeared inside the canyon top, while the slightly larger third appeared just above the street, both their centers lying closer to the leeward side of the canyon. Additional (much smaller) ones were observed inside the balcony cavities. b) The vortices (e.g. the main vortex) appeared to possess an inner core rotating as a "forced vortex" (i.e. solid body rotating air mass). In the leeward side they appeared to form "Rankine vortices", while in the windward side a shear layer zone was formed between the vortex and the façade. c) The central vortex rotated in the counter-clockwise direction with an angular velocity of $\omega_{1}=+0,324 \mathrm{rad} / \mathrm{s}$, the vortex near the leeward building and street corner rotated with an angular velocity of $\omega_{2}=-0,094 \mathrm{rad} / \mathrm{s}$. The smaller vortex near the leeward top corner rotated at a rate of $\omega_{3}=-0,072$ $\mathrm{rad} / \mathrm{s}$. d) The actual pollutant transport within a canyon cavity started from a dead zone near the street level, followed by an exponential reduction due to the flow diffusion imposed by the vortex structures. This was followed by a smaller dead zone near the roof while the final "wash out" was driven by the shear layer formed between the cavity flow and the outer wind.

In general, the balconies on the leeward building façade were the worst cases in the pollutant concentration levels, especially in the lower parts of the canyon. It was concluded that the balconies create vortices which trapped the air pollutants at lower heights. The multi-balcony configurations modified significantly the flow field and the relevant pollutant transport mechanisms.

The present study focused on a computational investigation of the effect of the galleries on the flow field structure and the vertical distribution of the concentration both near the building facades and on the centerline of the canyon. Numerical results are presented for various gallery and balcony combinations for an aspect ratio of $h / w=2.33$. They illustrate the formation of the vortices (i.e. number, nature, rotation rate) inside the canyon and the vertical concentration profiles of the aerosol particles which attributed to the complex wind flow structure and the physical layout of the street canyon. Finally, it is demonstrated that the presence of the galleries did not help the pollutant to escape from the canyon due to the lower dispersion of the pollutant and its accumulation inside the cavity. 


\section{METHODOLOGY}

\subsection{DOMAIN MODELING, GRID CHARACTERISTICS AND BOUNDARY CONDITIONS}

In the present study the street level galleries were added into the reference geometry (a narrow city canyon without balconies and an aspect ratio 2.33, as discussed in our recent paper (Karkoulias, et. al., 2019) to investigate how they affect the flow field inside the cavity and the distribution of the concentration on the building facades and the centreline of the canyon. The investigation was extended to other similar configurations by studying the combination between galleries and balconies. The results are presented in section 3 of this paper.

The canyon geometries employed in the present study are described in Table 1 . The street canyon configuration named "Geometry A" with balconies upon the leeward façade and galleries on both facades is illustrated in Figure 1

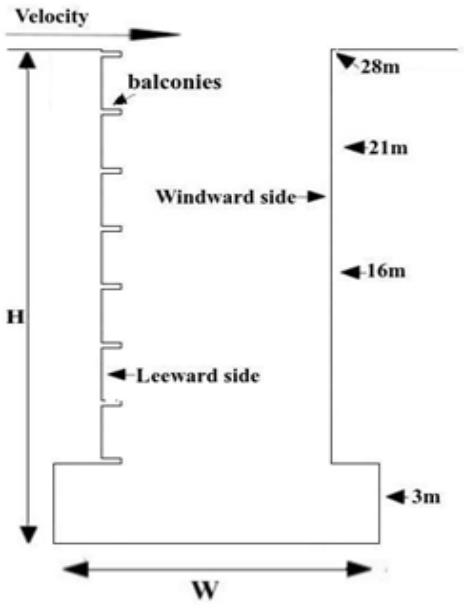

(a)

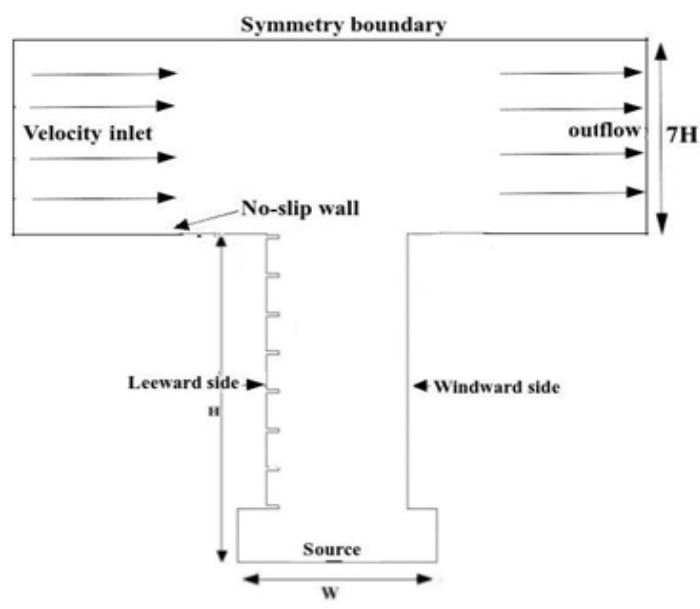

(b)

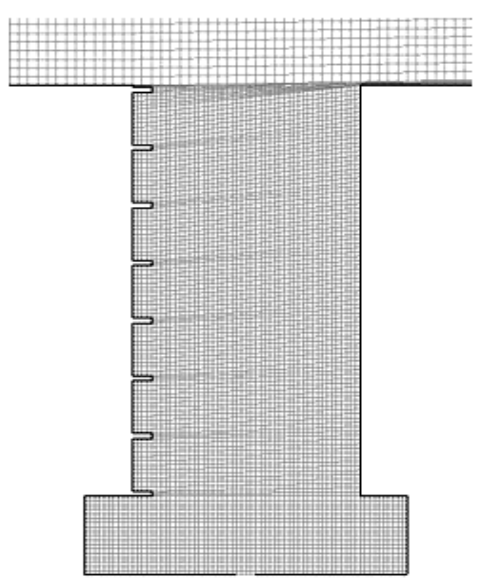

(c)

Figure 1: (a) Computational street canyon configuration, (b) Computational domain, (c) Grid of the Geometry A with galleries $(\mathrm{W}=12 \mathrm{~m} \mathrm{H}=28 \mathrm{~m})$

The undisturbed flow inside the computational domain, the distribution of the vehicular exhaust, the local source strength and the corresponding average $\mathrm{PM}_{10}$ emission rate, were defined in our previous paper (Karkoulias et al., 2019). The geometric characteristics of the canyon and the facades elements (e.g. the geometry of the balconies, the geometry of the source and the characteristics of the traffic) were described in the same paper.

The galleries penetrated $2.5 \mathrm{~m}$ into the interior of the building and they were $4.5 \mathrm{~m}$ in height (fig.1b). The prevailing wind direction was perpendicular to the long street canyon axis. As a result, the 3-D spatial domain was simplified into a two dimensional (2-D) one, while the wind speed above the roof-top level was set to be equal to 1.5 m/s (Fig. 1b). The building walls, the roofs and the street pavements were defined as "wall boundaries" (zero velocity and impermeability conditions), while the top boundary of the computational domain opposite the street was assigned as a symmetrical one.

The closure of the dynamic flow equations employed the steady state $\kappa-\varepsilon$ RNG (Re-Normalized Group theory) method (Kim and Baik, 2004). In order to achieve a greater accuracy in a shorter computational time, the flow domain was divided into 2 regions, each with its own grid. The street canyon (height $=28 \mathrm{~m}$, width = $12 \mathrm{~m}$ ) incorporated a finer structured Quad (Cartesian) grid of uniform spacing whereas for the remaining domain (above the canyon) incorporated a coarser structured mesh of tetrahedral elements (Fig. 1c). The mesh of the computational domain had 182098 cells, 365114 faces and 183025 nodes. 


\subsection{MODEL VALIDATION}

The validity of the numerical simulation employed in the present study is discussed in our previous publication (Karkoulias et al., 2019). It was assumed that the validation holds for the modified geometry as well. The fluent RANS code for complex architectural geometries was evaluated against wind tunnel experiments and field measurements in our previous paper. Comparisons demonstrate that the RANS results were overall in good agreement with the wind tunnel experiments and with the field measurements and could be used as basis for understanding the detailed flow dynamics.

\section{RESULTS AND DISCUSSION}

\subsection{THE EFFECT OF THE GALLERIES IN THE WIND FLOW STRUCTURE}

The four cavity geometries (Table 1) studied in our previous publication (Karkoulias et al., 2019) which highlighted the influence of the balconies on the flow field shown in Figure 2.

Table 1: The cases of the previous study

\begin{tabular}{|c|c|}
\hline Cases & Characteristics \\
\hline Reference Geometry & The narrow cavity without balconies with aspect ratio $\mathrm{h} / \mathrm{w}=2.33$ \\
\hline Geometry A & The Reference case with balconies on the leeward building façade \\
\hline Geometry B & The Reference case with balconies on the windward building façade \\
\hline Geometry C & The Reference case with balconies on both building facades \\
\hline
\end{tabular}

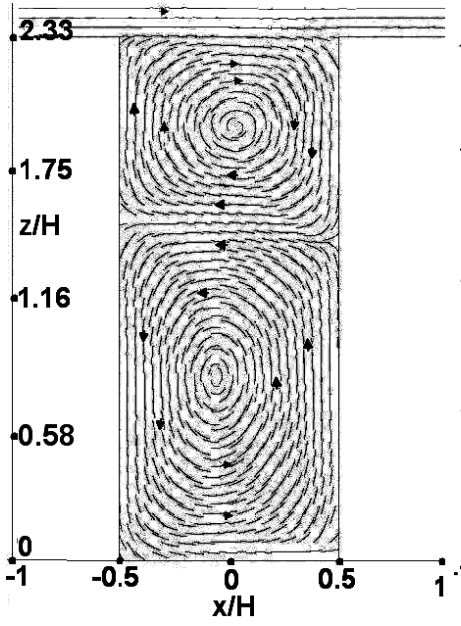

(a)

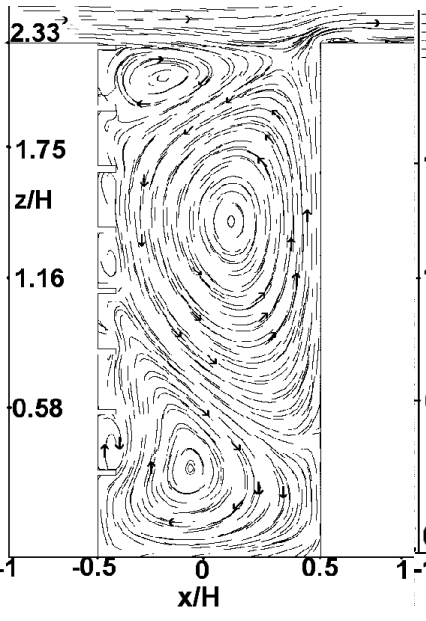

(b)

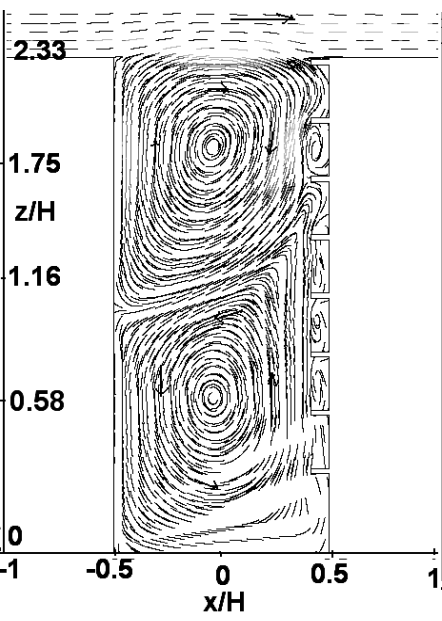

(c)

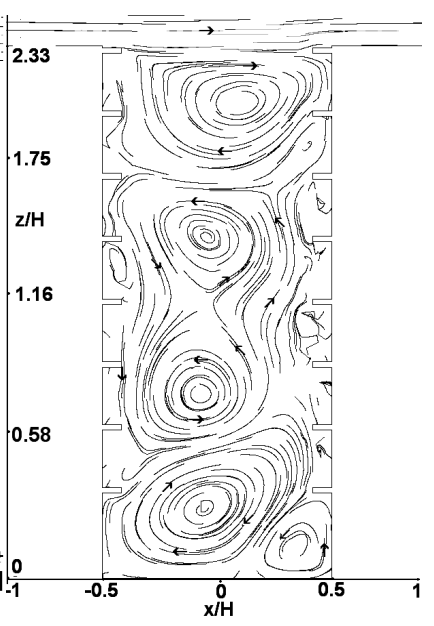

(d)

Figure 2: Flow field with different position of balconies in aspect ratio 2.33 in isothermal condition (a) Reference geometry, (b) Geometry A, (c) Geometry B, (d) Geometry C.

These same cavity geometries were employed in the present study to investigate the effect of galleries, in combination with the balconies, on the flow field and on the distribution of the concentration on both buildings facades and the canyon cavity centerline. 


\section{A. Karkoulias, P. E. Marazioti, D. P. Georgiou, and E. A. Maraziotis}

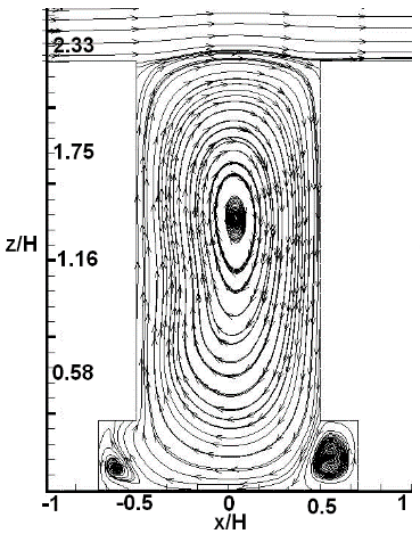

(a)

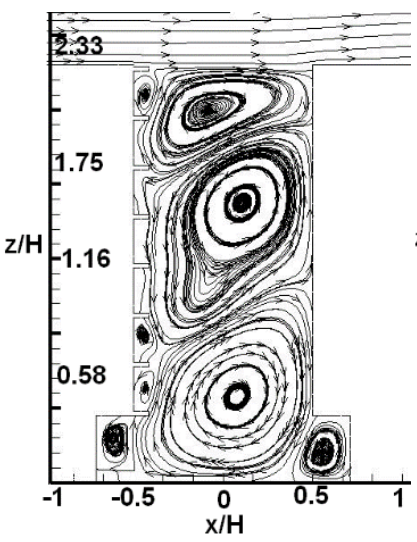

(b)

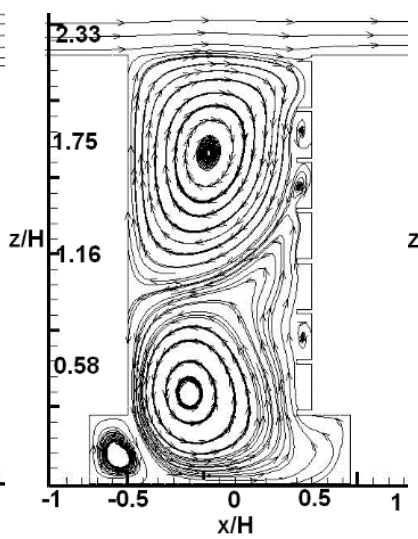

(c)

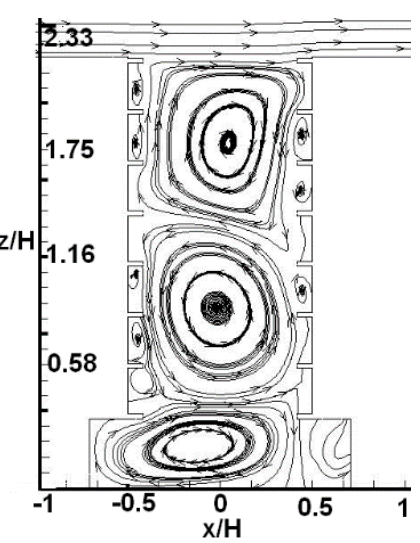

(d)

Figure 3: Flow field streamlines inside the canyon cavity with galleries and aspect ratio 2.33, (a) without balconies, (b) balconies on leeward side, (c) balconies on windward side, (d) balconies on both sides.

The climate of street canyons is primarily controlled by the micro-meteorological effects of the urban geometry rather than the mesoscale forces controlling the climate of the boundary layer (Hunter et al; 1992). The outer wind and the flow structures inside the canyon cavity do not correlate in a simple manner. The pollutant transfer requires the detailed knowledge of both the outer wind and the inner cavity flows to be analyzed.

The number of vortices, the position of their center and the angular velocity ( $\omega$ ) (to be discussed below) for the vortices inside the cavities without and with galleries are shown in Table 2:

Table 2: The number of vortices, the position of the vortex center and the angular rotational velocity for the canyons without and with galleries

\begin{tabular}{|c|c|c|c|}
\hline Geometry & $\begin{array}{l}\text { Number of } \\
\text { vortices }\end{array}$ & Position of vortex center* & $\begin{array}{l}\text { Angular rotational } \\
\text { velocity }\end{array}$ \\
\hline Reference & 2 & $\begin{array}{l}\text { upper: } x=+6.33 \mathrm{~m}, \mathrm{y}=24.22 \mathrm{~m} \\
\text { lower: } \mathrm{x}=+5.24 \mathrm{~m}, \mathrm{y}=+9.68 \mathrm{~m}\end{array}$ & $\begin{array}{l}\omega_{\text {upper }}=-0.16 \mathrm{rad} / \mathrm{s} \\
\omega_{\text {lower }}=+0.21 \mathrm{rad} / \mathrm{s}\end{array}$ \\
\hline A & 3 & $\begin{array}{l}\text { upper: } x=+4.28 \mathrm{~m}, \mathrm{y}=+25.99 \mathrm{~m} \\
\text { middle: } \mathrm{x}=+6.95 \mathrm{~m}, \mathrm{y}=+15.84 \mathrm{~m} \\
\text { lower: } \mathrm{x}=+5.58 \mathrm{~m}, \mathrm{y}=+4.28 \mathrm{~m}\end{array}$ & $\begin{aligned} \omega_{\text {upper }} & =-0,07 \mathrm{rad} / \mathrm{s} \\
\omega_{\text {middle }} & =+0.32 \mathrm{rad} / \mathrm{s} \\
\omega_{\text {lower }} & =-0.09 \mathrm{rad} / \mathrm{s}\end{aligned}$ \\
\hline B & 2 & $\begin{array}{c}\text { upper: } \mathrm{x}=+5.62 \mathrm{~m}, \mathrm{y}=+22.9 \mathrm{~m} \\
\text { lower: } \mathrm{x}=5.82 \mathrm{~m}, \mathrm{y}=+7.00 \mathrm{~m}\end{array}$ & $\begin{array}{c}\omega_{\text {upper }}=-0.39 \mathrm{rad} / \mathrm{s} \\
\omega_{\text {lower }}=+0.19 \mathrm{rad} / \mathrm{s}\end{array}$ \\
\hline $\mathrm{C}$ & 5 & $\begin{array}{c}\text { upper: } \mathrm{x}=+6.75 \mathrm{~m}, \mathrm{y}=+25.2 \mathrm{~m} \\
\text { middle up: } \mathrm{x}=+5.25 \mathrm{~m}, \mathrm{y}=+17.2 \mathrm{~m} \\
\text { middle down: } \mathrm{x}=+4.32 \mathrm{~m}, \mathrm{y}=+8.90 \mathrm{~m} \\
\text { lower: } \mathrm{x}=+5.19 \mathrm{~m}, \mathrm{y}=+3.42 \mathrm{~m} \\
\text { windward street corner: } \mathrm{x}=+9.82 \mathrm{~m} \text {, } \\
\mathrm{y}=+1.80 \mathrm{~m}\end{array}$ & $\begin{array}{c}\omega_{\text {upper }}=-0.16 \mathrm{rad} / \mathrm{s} \\
\omega_{\text {middle up }}=+0.02 \mathrm{rad} / \mathrm{s} \\
\omega_{\text {middle down }}=+0.09 \mathrm{rad} / \mathrm{s} \\
\omega_{\text {lower }}=-0.16 \mathrm{rad} / \mathrm{s} \\
\omega_{\text {windward corner }}=+0.21 \\
\mathrm{rad} / \mathrm{s}\end{array}$ \\
\hline $\begin{array}{l}\text { Reference with } \\
\text { galleries }\end{array}$ & 3 & $\begin{array}{c}\text { main: } \mathrm{x}=+6.44 \mathrm{~m}, \mathrm{y}=+17.72 \mathrm{~m} \\
\text { leeward gallery: } \mathrm{x}=-1.39 \mathrm{~m}, \mathrm{y}=+1.45 \mathrm{~m} \\
\text { windward gallery: } \mathrm{x}=+12.56 \mathrm{~m}, \\
\mathrm{y}=+2.08 \mathrm{~m}\end{array}$ & $\begin{array}{c}\omega_{\text {main }}=-0.75 \mathrm{rad} / \mathrm{s} \\
\omega_{\text {leeward gallery }}=+0.13 \\
\mathrm{rad} / \mathrm{s} \\
\omega_{\text {windward gallery }}=+0.31 \\
\mathrm{rad} / \mathrm{s}\end{array}$ \\
\hline A with galleries & 5 & $\begin{array}{c}\text { upper: } \mathrm{x}=+4.99 \mathrm{~m}, \mathrm{y}=+25.05 \mathrm{~m} \\
\text { middle: } \mathrm{x}=+7.22 \mathrm{~m}, \mathrm{y}=+17.79 \mathrm{~m} \\
\text { lower: } \mathrm{x}=+6.90 \mathrm{~m}, \mathrm{y}=+5.78 \mathrm{~m} \\
\text { leeward gallery: } \mathrm{x}=-1.34 \mathrm{~m}, \mathrm{y}=+2.97 \mathrm{~m} \\
\text { windward gallery: } \mathrm{x}=+12.69 \mathrm{~m}, \\
\mathrm{y}=+2.05 \mathrm{~m}\end{array}$ & $\begin{array}{c}\omega_{\text {upper }}=-0.76 \mathrm{rad} / \mathrm{s} \\
\omega_{\text {middle }}=+0.14 \mathrm{rad} / \mathrm{s} \\
\omega_{\text {lower }}=-0.23 \mathrm{rad} / \mathrm{s} \\
\omega_{\text {leeward gallery }}=+0.13 \\
\mathrm{rad} / \mathrm{s} \\
\begin{array}{c}\omega_{\text {windward gallery }}=+0.38 \\
\mathrm{rad} / \mathrm{s}\end{array}\end{array}$ \\
\hline
\end{tabular}


Effect of Galleries on The Wind Flow Structure and Pollutant Transport Within Street Canyons with or Without Facade Roughness Elements (Balconies)

\begin{tabular}{|c|c|c|c|}
\hline B with galleries & 3 & $\begin{array}{c}\text { upper: } \mathrm{x}=+5.19 \mathrm{~m}, \mathrm{y}=+21.72 \mathrm{~m} \\
\text { lower: } \mathrm{x}=+4.00 \mathrm{~m}, \mathrm{y}=+5.89 \mathrm{~m} \\
\text { leeward gallery: } \mathrm{x}=-0.71 \mathrm{~m}, \mathrm{y}=+1.81 \mathrm{~m}\end{array}$ & $\begin{array}{c}\omega_{\text {upper }}=-0.27 \mathrm{rad} / \mathrm{s} \\
\omega_{\text {lower }}=+0.33 \mathrm{rad} / \mathrm{s} \\
\omega_{\text {leeward gallery }}=-0.25 \\
\mathrm{rad} / \mathrm{s}\end{array}$ \\
\hline C with galleries & 3 & $\begin{array}{c}\text { upper: } \mathrm{x}=+6.47 \mathrm{~m}, \mathrm{y}=+22.53 \mathrm{~m} \\
\text { middle: } \mathrm{x}=+5.65 \mathrm{~m}, \mathrm{y}=+11.70 \mathrm{~m} \\
\text { lower: } \mathrm{x}=+4.62 \mathrm{~m}, \mathrm{y}=+2.77 \mathrm{~m}\end{array}$ & $\begin{array}{c}\omega_{\text {upper }}=-0.20 \mathrm{rad} / \mathrm{s} \\
\omega_{\text {middle }}=+0.34 \mathrm{rad} / \mathrm{s} \\
\omega_{\text {lower }}=-0.06 \mathrm{rad} / \mathrm{s}\end{array}$ \\
\hline
\end{tabular}

${ }^{*}$ The $\mathrm{x}$ coordinate was measured from the leeward side while the y coordinate was measured from the street level.

As it will become apparent, the presence of the galleries modifies the vortex structures and the associated particulate mass convection mechanism quite drastically. The nature of the vortices may be studied as follows:

\subsubsection{THE REFERENCE GEOMETRY WITH GALLERIES ON BOTH SIDES (FIG.3A)}

The addition of galleries into the reference Geometry formed three vortices (fig.3a). Fig. 4 illustrates the variation of the magnitude of the vertical component of the flow velocity along the horizontal line that pass through the centres of the vortices. This figure implies that:

The main vortices appeared to have an inner core rotating as a "forced vortex", i.e. the vertical velocity component $\left(\mathrm{u}_{\mathrm{y}}\right)$ increased with distance $(\mathrm{r})$ from the centre. In other words, the vortex contained a nearly solid mass that rotated with a nearly constant angular velocity $\left(\omega=\partial u_{y} / \partial r\right)$.

The main middle clockwise rotating vortex extended down from the level of the road up to the roof of the canyon and occupied most of its cross section. This vortex rotated with an angular velocity of $\omega_{\text {main }}=-0.75 \mathrm{rad} / \mathrm{s}$ which implies a period of rotation of the order of $8.37 \mathrm{~s}$.

Fig.4 demonstrates that in near the leeward side "Rankine" vortices were formed while near the windward side a shear layer zone was formed between the vortex and the façade. The small counterclockwise rotating vortices inside the galleries rotated with an angular velocity of $\omega_{\text {leeward gallery }}=+0.13 \mathrm{rad} / \mathrm{s}$ and $\omega_{\text {windward gallery }}=+0.31 \mathrm{rad} / \mathrm{s}$. The leeward gallery vortex had a period of rotation of the order of 48.3s while the windward gallery vortex had a period of the order of 20.2 seconds, i.e. at a much lower pace than the main one.
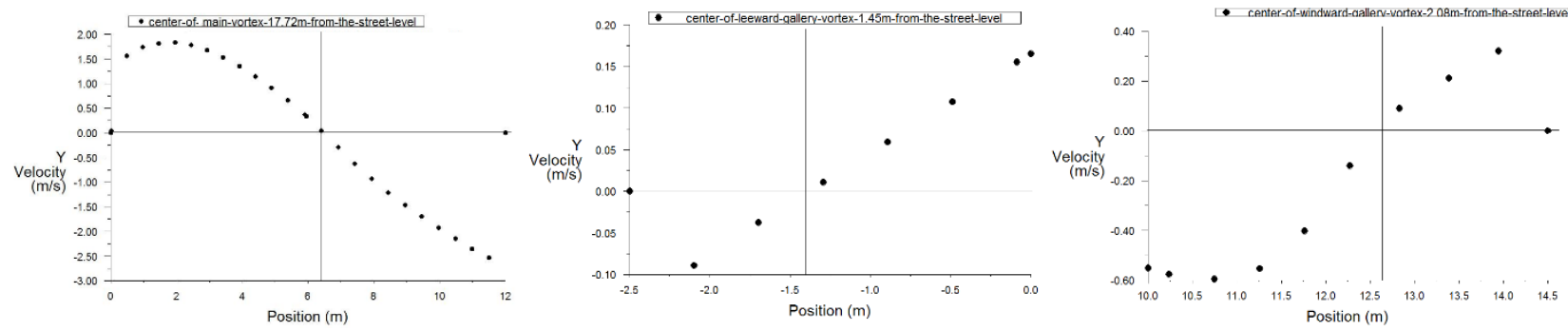

Figure 4: The y-velocity along horizontal line passing through the center of the main middle vortex, leeward and windward gallery vortex located at $17.72 \mathrm{~m}, 1.45 \mathrm{~m}$, and $2.08 \mathrm{~m}$ respectively away from the street level

\subsubsection{THE GEOMETRY A WITH GALLERIES ON BOTH SIDES (FIG.3B)}

In Geometry A with galleries, five vortices were formed (fig.3b). Three main vortices (i.e. the upper, the middle and the lower vortex) and two secondary vortices (i.e. the leeward and the windward gallery vortex) were formed inside the cavity. Fig. 5 illustrates the profile of the $u_{y}$ along the horizontal line that pass through the centres of the vortices. The results indicated that the lower main vortex rotated in the clockwise direction with an angular velocity of $\omega_{\text {lower }}=-0.23 \mathrm{rad} / \mathrm{s}$ which implies a period of rotation of the order of $27.30 \mathrm{~s}$. In other words, the centre of the vortex rotated at a constant rate of about 13.2 degrees per second. Fig.5 demonstrated that in the leeward side the nature of the vortex structures formed "Rankine vortices" (i.e. it appeared to be composed of an inner solid body rotating air mass that diffuses at the outer limits). On the other hand, near the windward side a shear layer zone was 


\section{A. Karkoulias, P. E. Marazioti, D. P. Georgiou, and E. A. Maraziotis}

formed between the vortex and the façade. The angular momentum of the rotating air masses dissipates within the shear zones, leading to a weakening of the linear vortices inside the canyon. Eventually the canyon vortices loose coherence as the core radius increases and the vortices expand to fill the entire region (Kingdon R., 2008). The inner part of the flow corresponds to a rigidly rotating core while the outer region becomes a free vortex. This prevents the velocity from becoming infinite at the center of rotation. At the same time, for a radial distance $r>R$ (where $R$ is the core radius), the model reverts to a free vortex, which allows for the velocity to decay at large distances. A Rankine vortex constitutes an amalgamation of the forced and free vortices profiles (Katopodes, N., 2019).

The results indicated that something similar occurs with the middle main vortex rotated in the counter clockwise direction with an angular velocity of $\omega_{\text {middle }}=+0.14 \mathrm{rad} / \mathrm{s}$ (i.e. a period of rotation equal to $44.85 \mathrm{~s}$ ). The centre of this vortex rotated at a constant rate of about 8.04 degrees per second.

The upper main vortex rotated in the clockwise direction with an angular velocity of $\omega_{\text {upper }}=-0.76 \mathrm{rad} / \mathrm{s}$ while the central one rotated at a constant rate of about 43.6 degrees per second. Apparently, the uppermost vortex rotated very fast (when compared to the other two) and this implies the presence of very strong shear phenomena all around its periphery. The most intensive upper main vortex transported the pollutants from the middle part of the canyon to the higher levels. The counter-clockwise vortices inside the galleries rotated with an angular velocity of $\omega_{\text {leeward }}$ gallery $=+0,13 \mathrm{rad} / \mathrm{s}$ and $\omega_{\text {windward gallery }}=+0,38 \mathrm{rad} / \mathrm{s}$. The centre of the leeward gallery vortex rotated at a constant rate of 7.46 degrees per second so it rotated at a similar rate with the lower main vortex. The centre of the windward gallery vortex rotated at a rate of 21.8 degrees per second which is much faster than the corresponding magnitude of the lower vortex.

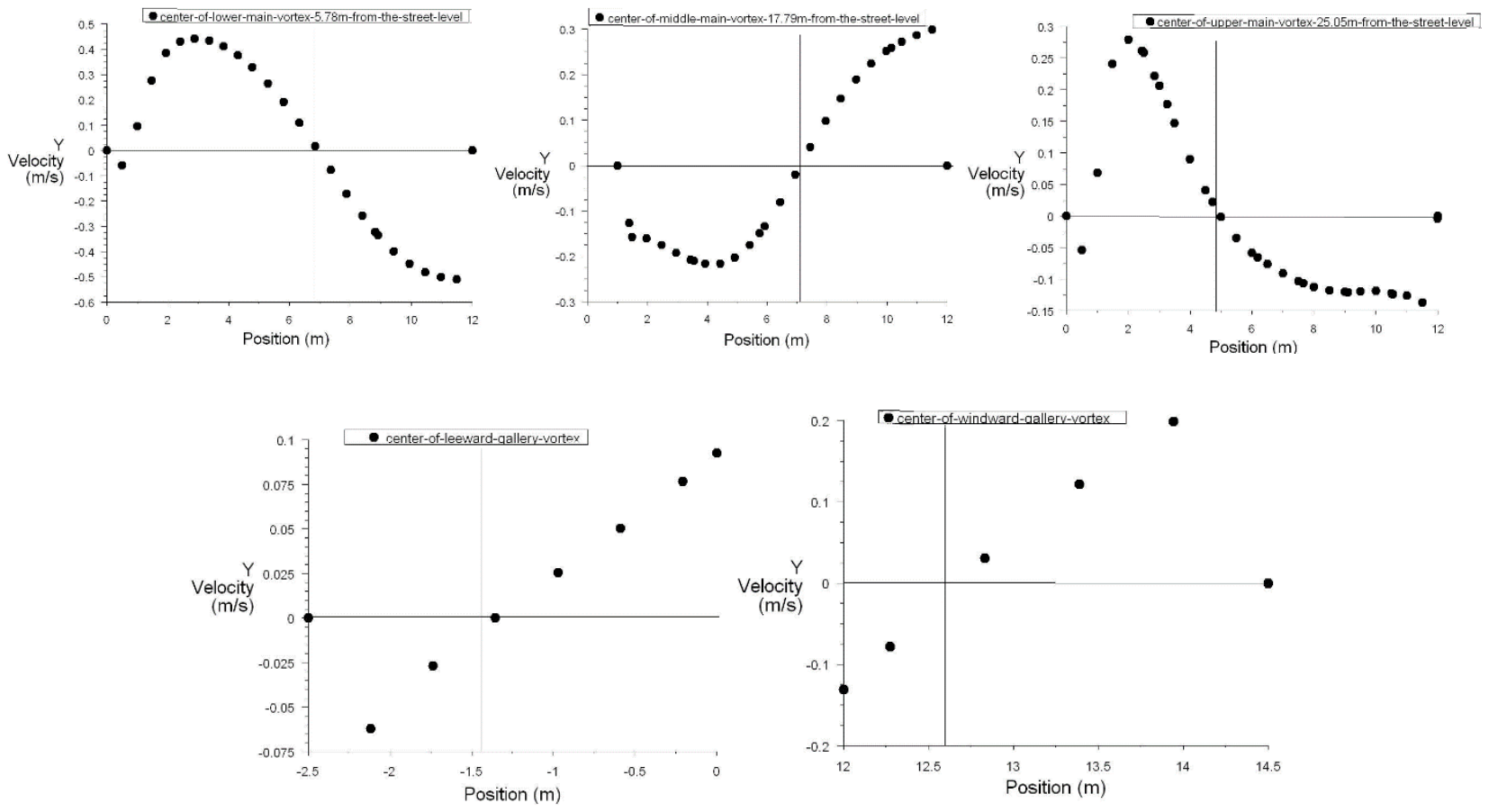

Figure 5: The y-velocity along the horizontal line passing through the center of the lower, middle, upper main vortex, leeward and windward gallery vortex located at $5.78 \mathrm{~m}, 17.79 \mathrm{~m}, 25.05 \mathrm{~m}, 2.97 \mathrm{~m}$, and $2.05 \mathrm{~m}$ respectively away from the street level

\subsubsection{THE GEOMETRY B WITH GALLERIES ON BOTH SIDES (FIG.3C)}

In Geometry B with galleries three vortices were formed (fig.3c). The main two counter rotating vortices were located inside the canyon while the third was embedded inside the gallery of the leeward building. The upper main vortex rotated in the clockwise direction with an angular velocity of $\omega_{\text {upper }}=-0.27 \mathrm{rad} / \mathrm{s}$. The rotation period was of the order of $23.2 \mathrm{~s}$ and the centre rotated at a constant rate of about 15.49 degrees per second. The counter-clockwise lower main vortex rotated with an angular velocity of $\omega_{\text {lower }}=+0.33 \mathrm{rad} / \mathrm{s}$. The rotation period of this vortex was $19 \mathrm{~s}$. The third clockwise rotating vortex was embedded inside the gallery of the leeward building. The angular velocity 
of this vortex was $\omega_{\text {leeward gallery }}=-0.25 \mathrm{rad} / \mathrm{s}$ (i.e. a rotational period of $25.1 \mathrm{~s}$ ) and the centre rotated at a constant rate of about 14.34 degrees per second.

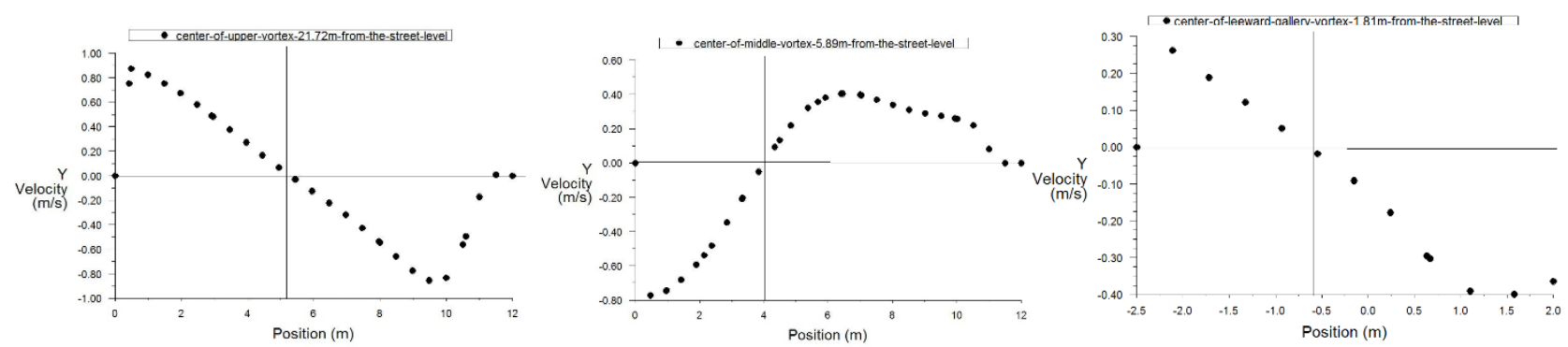

Figure 6: The y-velocity along horizontal line passing through the center of the upper, lower and leeward gallery vortex located at $21.72 \mathrm{~m}, 5.89 \mathrm{~m}$ and $1.81 \mathrm{~m}$ respectively away from the street level

\subsubsection{THE GEOMETRY C WITH GALLERIES ON BOTH SIDES (FIG.3D)}

When the galleries were added into Geometry $\mathrm{C}$, three main vortices were formed inside the canyon and some secondary vortices between the balconies (fig.3d). Figure 7 illustrates the profile of $\mathrm{u}_{\mathrm{y}}$ along the horizontal line that pass through the centres of the vortices. The results indicated that the upper clockwise rotating main vortex (extended up to the roof of the canyon), had an angular velocity $\omega_{\text {upper }}=-0.20 \mathrm{rad} / \mathrm{s}$ (i.e. a rotation period of $31,4 \mathrm{~s}$ ) while the central one rotated at a constant rate of about 11.47 degrees per second. The middle counterclockwise vortex rotated with an angular velocity of $\omega_{\text {middle }}=+0.34 \mathrm{rad} / \mathrm{s}$. The rotation period was about $18.47 \mathrm{~s}$ and the rotation rate was 19.50 degrees per second. The lower clockwise rotating vortex extended down to near the bottom of the cavity and rotated with an angular velocity of $\omega_{\text {lower }}=-0.06 \mathrm{rad} / \mathrm{s}$. The rotation period was about $104.6 \mathrm{~s}$ and the rotation rate was 3.44 degrees per second.

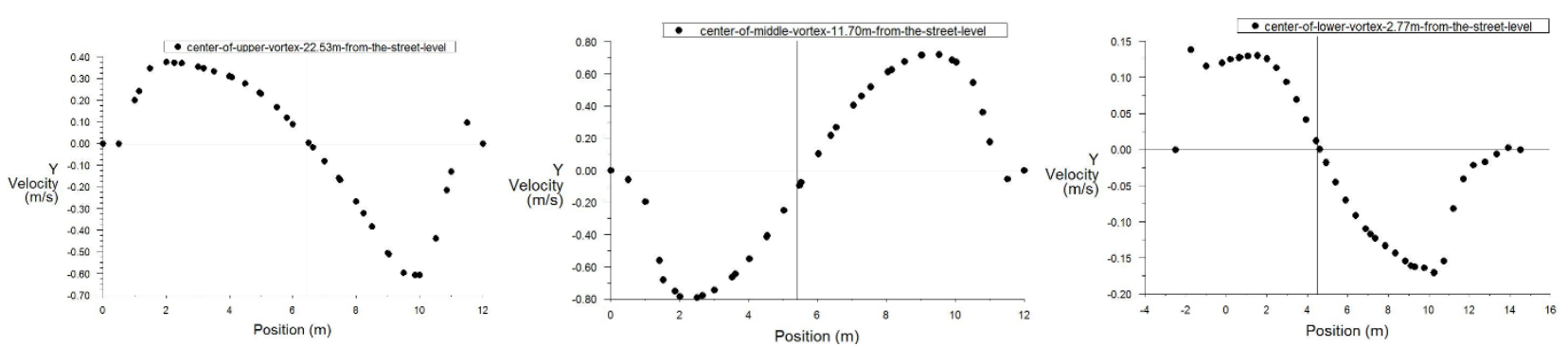

Figure 7: The y-velocity along horizontal line passing through the center of the upper, middle and lower vortex located at $22.53 \mathrm{~m}, 11.70 \mathrm{~m}$ and $2.77 \mathrm{~m}$ respectively away from the street level

From Figs 2, 3 and Table 2 it is obvious that the galleries affect the flow structure (i.e. number, position, and size of the vortices) inside the cavity. These changes are discussed below:

Inside the reference geometry with galleries the number of vortices and their position changed (three vortices versus two). Inside the cavity there was only one main vortex that occupied the cross section of the cavity. Its angular velocity was about six times higher than the velocity of the leeward gallery vortex and twice than the velocity of the windward gallery vortex. In the corresponding geometry without galleries the lower vortex had a higher angular velocity than the upper one which means that it had the potential to transfer mass to higher levels. Hence, it may be deduced that the lower vortices have a reduced potential to convect mass towards the main vortex.

In Geometry A with galleries, five vortices appeared (i.e. three inside the main section of the cavity and two in the galleries) against the three inside the respective geometry without galleries. The presence of the galleries did not influence the flow structure of the three main vortices significantly but only changed the size and their angular velocities. The angular velocity of the upper and lower vortex was higher than the middle one. In the configuration without galleries the opposite had been observed.

The galleries in Geometry B modified the number of the vortices (three versus two) creating a vortex inside the leeward building gallery and shifting the center of the lower vortex downwards and closer to the leeward facade. 


\section{A. Karkoulias, P. E. Marazioti, D. P. Georgiou, and E. A. Maraziotis}

The angular velocity of the lower vortex was somewhat greater than the upper while in the case without galleries the lower vortex had the half angular velocity than the upper one.

The galleries in the Geometry $\mathrm{C}$ were also modified the flow field structure (i.e. three vortices versus five). The lower vortex extended from the leeward gallery to the entrance of the windward gallery, while the two middle vortices were replaced by a larger one. The angular velocity of the middle vortex was higher than the upper and the lower vortex. Especially the angular velocity of the lower vortex was about five times smaller than the middle one. In the corresponding geometry without galleries the upper and the lower vortex had the same angular velocity which was much higher than the angular velocity of the middle ones.

\subsection{INVESTIGATION OF THE AIR POLLUTANT TRANSPORT MECHANISM AND COMPARISON BETWEEN THE GEOMETRY A WITH AND WITHOUT GALLERIES}

A further discussion of Geometry A with galleries is given below because the corresponding geometry without galleries had been studied numerically and experimentally in our previous work. Also, the addition of the galleries did not significantly change the structure of the cavity flow. That is, the number of the main vortices in the cavity (except the vortices created in the galleries) was the same. Also, the centers of the three vortices as shown in Table 2 are approximately in the same position. Therefore, the main effect comes from the relative sizes of the vortices.

In the Geometry A with galleries (fig.3b) the results indicated that the middle vortex became smaller in size while the size of the other two was increased. The lower vortex transported the pollutant to the leeward side from the street level up to the $8 \mathrm{~m}$ level. The middle vortex transported the pollutant to the windward side from $8 \mathrm{~m}$ level up to the $25 \mathrm{~m}$ level and the upper one transported the pollutant out of the canyon. In general, in the geometry A with galleries the mechanism of the vortices makes the ventilation of the canyon difficult. The effect of the galleries was immediately apparent by comparing the angular velocities of the vortices presented in the above paragraph. Therefore, the vortex in the gallery of the leeward building had a lower angular velocity than the lower main vortex. Thus, the vortex had a little potential and the pollutant could not be transported out of the gallery. The result was the accumulation of the pollutants in this area. Also, the vortex in the gallery of the windward building had a higher angular velocity than the lower main vortex. The pollutant was therefore transported from the windward gallery to the bottom of the cavity. The lower main vortex was more intensive than the middle one and transported the pollutant to the leeward side and to the upper levels. Finally, the pollutant was concentrated on the windward side because the middle vortex had lower angular velocity than the upper one. So, the middle vortex did not have the potential to transport the pollutant to the upper vortex. Due to the high intensity of the upper vortex the concentration near the top of the cavity decreased because the pollutant escaped from this area.

Fig. 8 illustrated the results of the computational simulation for the horizontal distribution of the pollutant concentration at the height of $5.78 \mathrm{~m}, 17.79 \mathrm{~m}, 25.05 \mathrm{~m}, 2.97 \mathrm{~m}$ and $2.05 \mathrm{~m}$ above the street level, i.e. the level of the horizontal line passing through the center of the lower, middle, upper main vortex and leeward and windward gallery vortex respectively.

The computational results indicated that the clockwise rotating lower main vortex generates antisymmetric distributions of the pollutant concentrations. The maximum near the leeward façade is about of $14.5 \mu \mathrm{gr} / \mathrm{m}^{3}$ and a corresponding minimum near the windward façade is about of $12.3 \mu \mathrm{gr} / \mathrm{m}^{3}$.

The counter-clockwise rotating middle main vortex generates antisymmetric distributions of the pollutant concentrations with a maximum near the windward building facade of the order of $10.75 \mu \mathrm{gr} / \mathrm{m}^{3}$ and a minimum near the leeward façade of the order of $8.3 \mu \mathrm{gr} / \mathrm{m}^{3}$. The action of this vortex leads to pollutant accumulation near the windward building façade. These data imply that the middle main vortex extreme concentrations were reduced by nearly $12.6 \%$ on the windward side and $8.4 \%$ on the leeward side when compared to the lower vortex extreme concentrations.

The clockwise rotating upper main vortex generated similar distributions of pollutant concentrations with those of the lower vortex. The maximum near the leeward façade was of the order of $7.3 \mu \mathrm{gr} / \mathrm{m}^{3} \mathrm{while}$ the corresponding minimum near the windward façade was of the order of $4.1 \mu \mathrm{gr} / \mathrm{m}^{3}$. The upper main vortex extreme concentrations were reduced by nearly $61.8 \%$ on the windward side and $15.6 \%$ on the leeward side compared to the middle vortex extreme concentrations. So, the upper, clockwise rotating vortex did not affect the pollutant concentrations near the leeward facade dramatically comparing with the windward facade. 
The leeward gallery vortex generated a maximum in the pollutant distribution of the order of $15.74 \mu \mathrm{gr} / \mathrm{m}^{3}$ near the entrance of the gallery. The minimum mass concentration near the leeward wall was $15.66 \mu \mathrm{gr} / \mathrm{m}^{3}$. Inside the opposite gallery (i.e. the windward gallery), the vortex generated a maximum mass concentration near the windward wall of the order of $12.53 \mu \mathrm{gr} / \mathrm{m}^{3}$ and a minimum near the entrance of the gallery of the order of $12.5 \mu \mathrm{gr} / \mathrm{m}^{3}$. These data imply that pollutant accumulated inside both galleries. In other words, the galleries do not help the pollutants to escape. On the contrary, the mass concentration is increased within the bottom of the canyon.
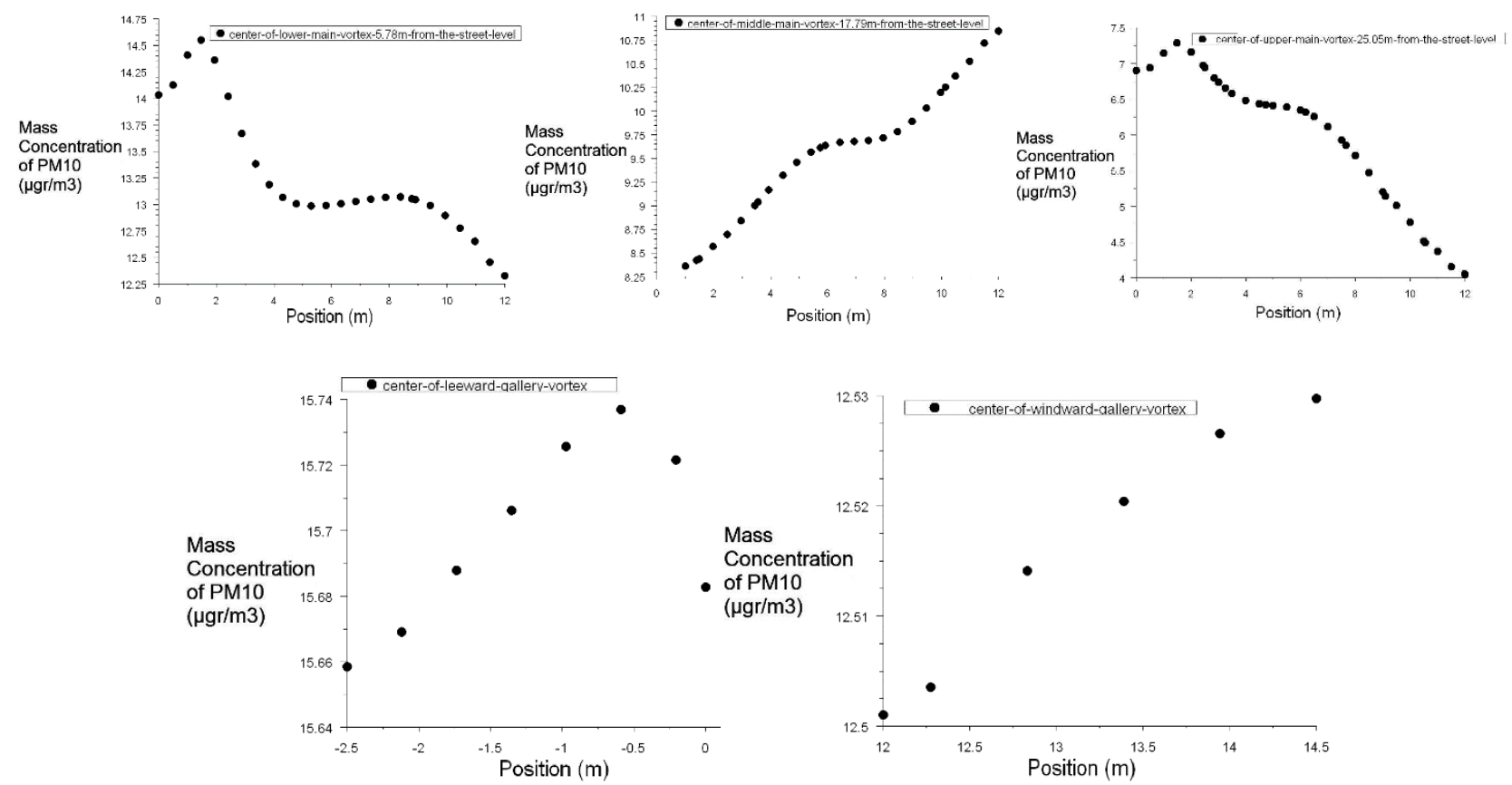

Figure 8: Mass concentration of $\mathrm{PM}_{10}\left(\mu \mathrm{gr} / \mathrm{m}^{3}\right)$ on the horizontal plane passing through the center of the lower, middle, upper main vortex, leeward and windward gallery vortex located at $5.78 \mathrm{~m}, 17.79 \mathrm{~m}$ and $25.05 \mathrm{~m}, 2.97 \mathrm{~m}$ and $2.05 \mathrm{~m}$ respectively from the street level.

Table 3 records the percentage reduction of the vortex extreme concentrations from vortex to vortex, resulted from a comparison of the data presented in Figure 8 for Geometry A with galleries and Geometry A studied in our previous paper (Karkoulias et. al., 2019).

Table 3: The percentage reduction of the vortex extreme concentrations from vortex to vortex in the leeward and windward side for the Geometry A with galleries and Geometry A

\begin{tabular}{|c|c|c|c|}
\hline Geometry & Vortex & side & $\begin{array}{l}\text { Percentage reduction of the vortex extreme concentrations } \\
\qquad(\%)\end{array}$ \\
\hline \multirow{3}{*}{$\begin{array}{l}\text { A with } \\
\text { galleries }\end{array}$} & Middle & Leeward & 8.4 \\
\hline & $\begin{array}{l}\text { comparing } \\
\text { to lower }\end{array}$ & Windward & 12.6 \\
\hline & $\begin{array}{l}\text { Upper comparing } \\
\text { to middle }\end{array}$ & $\begin{array}{c}\text { Leeward } \\
\text { Windward }\end{array}$ & $\begin{array}{l}15.6 \\
61.8\end{array}$ \\
\hline \multirow{3}{*}{ A } & Middle & Leeward & 80 \\
\hline & $\begin{array}{l}\text { comparing } \\
\text { to lower }\end{array}$ & Windward & 25 \\
\hline & $\begin{array}{l}\text { Upper comparing } \\
\text { to middle }\end{array}$ & $\begin{array}{l}\text { Leeward } \\
\text { Windward }\end{array}$ & $\begin{array}{c}28.57 \\
6.25\end{array}$ \\
\hline
\end{tabular}




\section{A. Karkoulias, P. E. Marazioti, D. P. Georgiou, and E. A. Maraziotis}

The vertical profile of Mass Concentration of $\mathrm{PM}_{10}$ near the windward building façade (fig. 9b) was somewhat interpreted by the $u_{y}$ profile (fig. $9 \mathrm{a}$ ). The concentration exhibited to remain constant up to the height of $7 \mathrm{~m}$ above the street level and then decreased up to the height of $18 \mathrm{~m}$. The $\mathrm{u}_{\mathrm{y}}$ profile justifies this reduction. From the height of $18 \mathrm{~m}$ up to the $23 \mathrm{~m}$, the concentration remained almost constant while the $\mathrm{u}_{\mathrm{y}}$ was decrease. Then the concentration was followed by a reduction while in the last meter, a sharp decrease was observed due to the upward flow and the external flow.

The $\mathrm{PM}_{10}$ Mass Concentration vertical profile near the leeward building façade (fig. $9 \mathrm{~b}$ ) was interpreted as follows: The increase of the $u_{y}$ (fig. 9a) along the positive direction led to the reduction of the concentration up to $3 \mathrm{~m}$. The distribution of the concentration up to $6 \mathrm{~m}$ was almost constant while then the increase in velocity along the negative direction led to a further decrease in concentration up to $12 \mathrm{~m}$. From there the concentration did not change due to the $\mathrm{u}_{\mathrm{y}}$ which was constant. The concentration continued to remain almost constant with a slight decrease up to $27 \mathrm{~m}$. A sharp decrease in the concentration was observed over the uppermost meter due to the upward flow - external flow interaction.

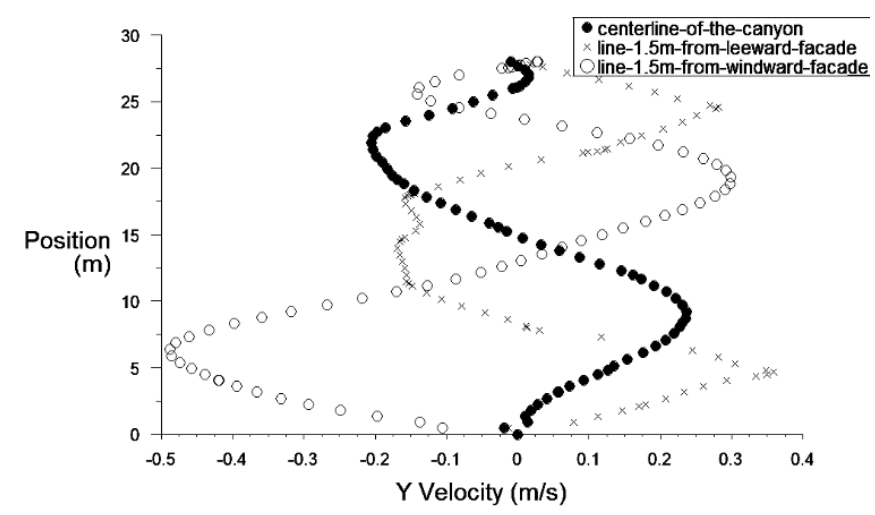

(a)

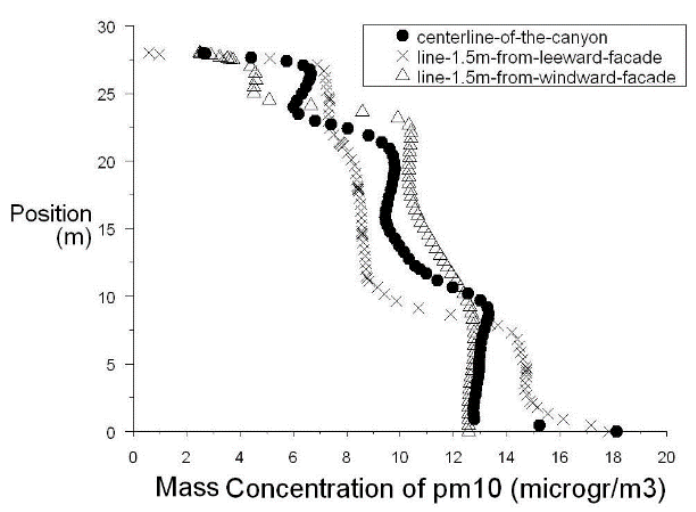

(b)

Figure 9: (a) Vertical profiles of $\mathrm{u}_{\mathrm{y}}$ and (b) Mass concentration of $\mathrm{PM}_{10}$ in $\mu \mathrm{gr} / \mathrm{m}^{3}$ at $1.5 \mathrm{~m}$ away from the leeward and windward façade and the centerline of the canyon in the Geometry A with galleries

The $u_{y}$ profile in Fig. 9a justifies the concentration profile in Fig. 9b along the centerline of the canyon in Geometry A with galleries. The concentration initially decreased over the first two meters in height followed by an increase up to the height of $9 \mathrm{~m}$. The subsequent decrease in $u_{y}$ caused a decrease in concentration up to $14 \mathrm{~m}$. At this point the flow direction of the $\mathrm{u}_{\mathrm{y}}$ changed and the concentration increased up to $21 \mathrm{~m}$. $\mathrm{U}_{\mathrm{y}}$ decreased up to about the $25.5 \mathrm{~m}$ level in parallel with the concentration to be followed by a sharp concentration reduction all the way up to the roof of the canyon.

In review, it is concluded that the air pollutant transport-dispersion mechanism consisted of three steps:

1) A dead zone was generated at the bottom of the canyon and the concentration of the pollutant in this region was increased by the presence of the galleries. This presence affected the flow field in such a way that made more difficult the upward movement of the pollutants to higher levels.

2) The enhanced mixing in the middle of the canyon due to the rotation of the vortices constituted the second step. The solid mass rotation of the vortices generated very strong shearing among their outer boundaries that not only diffused pollutant mass from vortex to vortex but in addition convected the pollutants forcing them to attach on the buildings facades.

3) A shear layer zone was created at the top of the canyon between the roof top level of the canyon and the upper wind external flow.

\subsection{THE VERTICAL DISTRIBUTION OF THE CONCENTRATION ON BOTH BUILDING FACADES AND THE CENTERLINE OF THE CANYON}

In the Reference geometry with galleries the middle-height vortex initially transported the pollutant towards the leeward facade, to be followed by a similar convection on the windward facade. The concentration of the $\mathrm{PM}_{10}$ 
near the latter remained almost constant from the ground level up to the height of about 24 meters. Above this height, the concentration decreased sharply up to the 28 meters, because the pollutants diffused to the outer atmosphere, as the vortex interacted with the outer free wind flow through the free shear layer. In the leeward building façade, the concentration decreased from the street level up to the $3 \mathrm{~m}$ one, remaining constant above it up to the height of $15 \mathrm{~m}$. Finally, it increased up to $23 \mathrm{~m}$ to be followed by a sharp drop up to the top of the canyon due to the vortex contact with the upper boundary layer (fig.10a).

The Geometry A with galleries data were discussed in detail in section 3.2 and the distribution of the $\mathrm{PM}_{10}$ mass concentration near the leeward and windward façades as well as along the canyon centerline are illustrated in figure $9 b$.

The Geometry B with galleries flow field was also modified so that the vertical distribution of concentration on the building facades was as follows: near the windward façade the concentration decreased between the street level and the $16 \mathrm{~m}$ height, followed by a sharp decrease up to the $22 \mathrm{~m}$ height. Finally, it remained constant from the 22 $\mathrm{m}$ height up to the height of $26 \mathrm{~m}$. Along the last two meters appeared a sharp decrease in concentration up to the roof of the canyon. At the leeward facade the concentration evolved as follows: initially it increased from a low magnitude on the street level up to approximately the $8 \mathrm{~m}$ height, followed by a sharp decrease up to the height of $16 \mathrm{~m}$, above which it remained was almost constant up to a height of $24 \mathrm{~m}$. Finally, along the last four meters the concentration increased steadily up to the top of the canyon (fig. 10b). The leeward gallery vortex contributed to the increased particle concentration within the low heights of the building. On the opposite side, the upper main vortex contributed to an increased particle concentration along the upper floors of the same building.

In the most complex scenario (i.e. Geometry $\mathrm{C}$ with galleries), the mechanism of the vortices does not help the pollutant to escape from the canyon. From the corresponding figure 10c the following results were obtained: At the leeward building façade the concentration initially increased up to the height of $5 \mathrm{~m}$ and then decreased sharply up to the height of approximately $8 \mathrm{~m}$. Above it the concentration decreases at a low rate up to the top of the canyon. At the windward building façade, the concentration maintained an almost constant value up to the height of $6 \mathrm{~m}$ and then decreased up to the height of $14 \mathrm{~m}$. Beyond that the concentration decreased sharply up to the height of 17 meters. Finally, it maintained a constant value up to the roof of the canyon. In general, the galleries made the escape of the pollutants from the lower heights more difficult. In other words, the concentration was maintained at high levels near the street especially at a height where humans breathe.

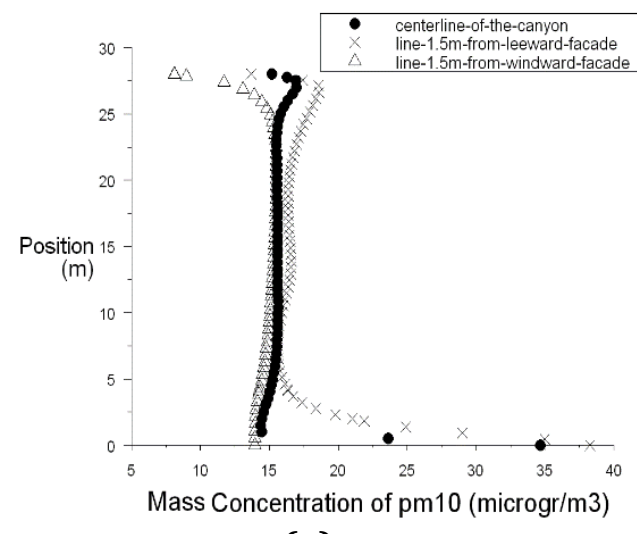

(a)

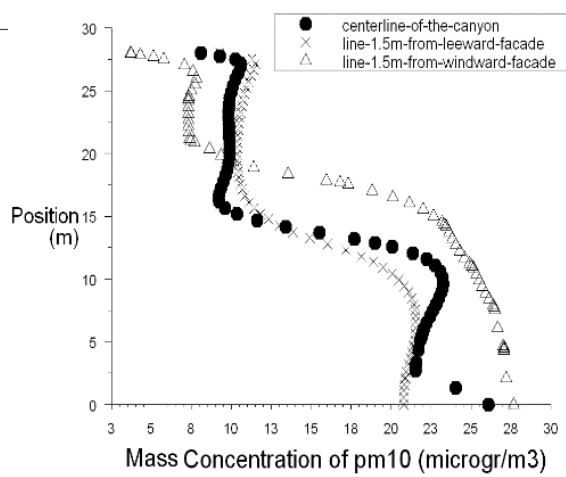

(b)

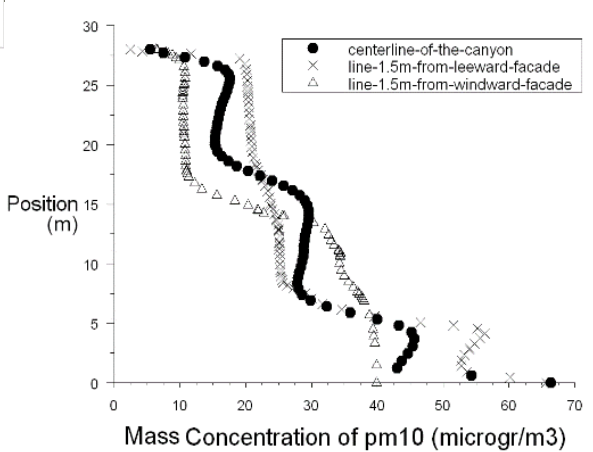

(c)

Figure 10: Mass concentration of $\mathrm{PM}_{10}$ in $\mu \mathrm{gr} / \mathrm{m}^{3}$ at $1.5 \mathrm{~m}$ away from the windward and leeward building façade and in the centerline of the canyon with galleries (a) Reference geometry, (b) Geometry B, (c) Geometry C.

From the results above, the deviation of the mass concentration between the street level and the roof of the canyon in the leeward and windward side and in the centerline was calculated. Table 4 below presents the results for the geometries studied above with galleries and those without galleries studied in a previous work (Karkoulias et al., 2019). 
Table 4: The percentage reduction of the mass concentration between the street level and the roof of the canyon in the leeward and windward side and the centerline of the canyon

\begin{tabular}{|c|c|c|c|c|c|c|c|c|}
\cline { 2 - 9 } \multicolumn{1}{c|}{ side } & \multicolumn{8}{c|}{ Percentage reduction of the concentration (\%) } \\
geometry & $\begin{array}{c}\text { Reference } \\
\text { geometry } \\
\text { with } \\
\text { galleries }\end{array}$ & $\begin{array}{c}\text { Geometry } \\
\mathrm{A}\end{array}$ & $\begin{array}{c}\text { Geometry } \\
\text { A with } \\
\text { galleries }\end{array}$ & $\begin{array}{c}\text { Geometry } \\
\mathrm{B}\end{array}$ & $\begin{array}{c}\text { Geometry } \\
\text { B with } \\
\text { galleries }\end{array}$ & $\begin{array}{c}\text { Geometry } \\
\text { C }\end{array}$ & $\begin{array}{c}\text { Geometry } \\
\text { C with } \\
\text { galleries }\end{array}$ \\
\hline Leeward & 66.6 & 55.2 & 74.3 & 61.1 & 75.0 & 47.6 & 82.2 & 67.1 \\
\hline Windward & 69.4 & 28.5 & 44.4 & 60.0 & 76.9 & 67.8 & 92.6 & 75.0 \\
\hline Centerline & 73.6 & 6.0 & 64.1 & 46.1 & 87.3 & 60.0 & 93.6 & 55.8 \\
\hline
\end{tabular}

The major findings may be reviewed as follows:

1) In general, the galleries proved to be another important factor affecting the wind flow structures. In contrast to the simple geometry without roughness, the multi-balcony configurations with galleries significantly modified the flow field and the relevant pollutant transport mechanisms. The presence of the galleries did not help the pollutant to escape from the canyon.

2) In many of the above figures (fig. 9b, 10) illustrated the same tendency as the Geometry A in which the field measurements were made. More specifically, the vertical distribution of the concentration did not decrease exponentially with the height but there were intervals in which it increased and burdened the adjacent area.

3) The addition of the galleries changed the number, the position and the rotation rate of the vortices. In Geometry A with galleries the middle vortex acquired less intensity than the corresponding one in the Geometry A. This means less dispersion of the pollutant and its accumulation in the middle of the cavity.

4) In Geometry A with galleries the concentration decreased by $8.4 \%$ at the height of the center of the middle vortex on the leeward side, compared to the $80 \%$ observed_in the Geometry A with no galleries. On the windward side, at the same height, the concentration decreased by $12.6 \%$ compared to the $25 \%$ observed in the corresponding geometry without galleries.

5) The deviation of the mass concentration between the street level and the roof of the canyon in the leeward and windward side as well as the centerline of the canyon, in geometries with galleries, was smaller than that of the corresponding geometries without galleries (Table 4).

6) The pollutant transport within a canyon cavity started from a dead zone near the street level, followed by an exponential reduction due to the flow diffusion imposed by the vortex structures. This was followed by a smaller dead zone near the roof while the final "wash out" was driven by the shear layer between the cavity flow and the outer wind.

\section{CONCLUSIONS}

Galleries incorporated on both building facades of a street canyon influence the air quality in it. The presence of galleries modified the flow field inside the canyon and indicates a significant influence on the mass concentration distribution of the polluting particles. The most relevant effect on the mass transfer rate from the street level to the roof level was the presence, induced by galleries and balconies, of several vortices in the street canyon that reduced the overhaul mass transfer.

The surface roughness of the building facades affect the flow features over and within the urban street canyons and as a consequence influence the mean and turbulent exchanges at the pedestrian level. The façade elements such as galleries produced lower mixing and so, they made the escape of pollutants difficult. Therefore, it appeared reasonable to suggest that through a formal exploration of buildings geometries, the ventilation potentional of urban canyons could be increased leading to an improvement of the air quality within the street canyon.

\section{SOURCES OF FUNDING}

This research received no specific grant from any funding agency in the public, commercial, or not-for-profit sectors. 
Effect of Galleries on The Wind Flow Structure and Pollutant Transport Within Street Canyons with or Without Facade Roughness Elements (Balconies)

\section{CONFLICT OF INTEREST}

The author have declared that no competing interests exist.

\section{ACKNOWLEDGMENT}

The authors would like to thank the Thermal Engines Laboratory of the Department of Mechanical Engineering and Aeronautics at the University of Patras, for their permission to use their licensed latest version of the ANSYSFluent suite.

\section{REFERENCES}

[1] Ai, Z., Mak, C., Niu, J., Li, Z. The assessment of the performance of balconies using computational fluid dynamics. Build. Serv. Eng. Technol. 32, 2011, 229-243.

[2] Ai, Z., Mak, C., Niu, J. Numerical investigation of wind-induced airflow and interunit dispersion characteristics in multistory residential buildings. Indoor Air 23, 2013, 417-429.

[3] Chand, I., Bhargava, P.K., Krishak, N.L.V. Effect of balconies on ventilation inducing aeromotive force on lowrise buildings. Building and Environment 33, 1998, 385-396.

[4] Cheng, Z., Luo, L., Wang, S., Wang, Y., Sharma, S., Shimadera, H., Wang, X., Bressi, M., de Miranda, R., Jiang, J., Zhou, W., Fajardo, O., Yan, N., Hao, J. Status and characteristics of ambient PM2.5 pollution in global megacities. Environ. Int. 89-90, 2016, 212-221

[5] Dockery, D., Pope, C., Xu, X., Spengler, J., Ware, J., Fay, M., Ferris, B., Speizer, F. An association between air pollution and mortality in six U.S. cities. N. Engl. J. Med. 329, 1993, 1753-1759.

[6] Fluent, (Version 6.2) - User's Manual, 2005. <http://www.fluent.com>.

[7] Gullbrekken, L., Uvslekk, S., Kvande, T., Petterson, K., Time, B. Wind pressure coefficients for roof ventilation purposes. Journal of Wind Engineering and Industrial Aerodynamics 175, 2018, 144-152.

[8] Hales, S., Blakely, T., Woodward, A. Air Pollution and mortality in New Zealand: cohort study. J. Epidemiol. Community Health 66, 2010, 468-473.

[9] Hunter LJ, Johnson GT and Watson ID. An investigation of three-dimensional characteristics of flow regimes within the urban canyon. Atmospheric Environment 26B, 1992, 425-432.

[10] Karkoulias, V.A., Marazioti, P.E., Georgiou, D.P., Maraziotis, E.A. Computational Fluid Dynamics modelling of the trace elements dispersion and comparison with measurements in a street canyon with balconies in the city of Patras, Greece. Atmospheric Environment 223, 2019, 117210.

[11] Katopodes, D. N. Free Surface Flow: Environmental Fluid Mechanics, Book. Chapter 7 - Vorticity Dynamics, 2019, Pages 516-565.

[12] Kim, J.J., Baik, J.J. A numerical study of the effects of ambient wind direction on flow and dispersion in urban

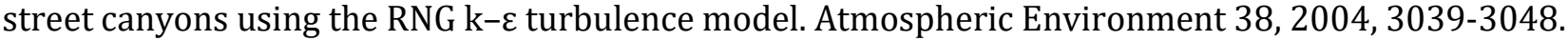

[13] Kingdon R. http://idealectic.com/idealectic/TurbulentRankineVortices.pdf, April 2008.

[14] Liaguno-Munitxa, M., Bou-Zeid, E., Hultmark, M. The influence on building geometry on street canyon air flow: validation of large eddy simulations against wind tunnel experiments. Journal of Wind Engineering and Industrial Aerodynamics 165, 2017, 115-130.

[15] Lelieveld, J., Evans, J., Fnais, M., Giannadaki, D., Pozzer, A. The contribution of outdoor air pollution sources to premature mortality on a global scale. Nature 525 (7569), 2015, 367-371.

[16] Montazeri, H., Blocken, B., Janssen, W.D., van Hooff, T. CFD evaluation of new second-skin facade concept for wind comfort on building balconies: Case study for the Park Tower in Antwerp. Building and Environment 68, 2013, 179-192.

[17] Montazeri, H., Blocken, B. CFD simulation of wind-induced pressure coefficients on buildings with and without balconies: validation and sensitivity analysis. Building and Environment 60, 2013, 137-149.

[18] Montazeri, H., Blocken, B. Extension of generalized forced convective heat transfer coefficient expressions for isolated buildings taking into account oblique wind directions. Building and Environment 140, 2018, 194-208. 
[19] Murena, F., Mele, B. Effect of balconies on air quality in deep street canyons. Atmospheric Pollution Research xxx, 2016, 1-9.

[20] Ramponi, R., Angelotti, A., Blocken, B. Energy saving potential of night ventilation: sensitivity to pressure coefficients for different European climates. Appl. Energy 123, 2014, 185-195.

[21] Silva, R., West, J., Zhang, Y., Anenberg, S., Lamarque, J.-F., Shindell, D., Collins, W., Dalsoren, S., Faluvegi, G., Folberth, G., Horowitz, L., Nagashima, T., Naik, V., Rumbold, S., Skeie, R., Sudo, K., Takemura, T., Bergmann, D., Cameron-Smith, P., Cionni, I., Doherty, R., Eyring, V., Josse, B., Mackenzie, I., Plummer, D., Righi, M., Stevenson, D., Strode, S., Szopa, S., Zeng, G. Global premature mortality due to anthropogenic outdoor air pollution and the contribution of past climate change. Environ. Res. Lett. 8 (3), 2013, 1-11.

[22] Zheng, X., Montazeri, H., Blocken, B. CFD simulations of wind flow and mean surface pressure for buildings with balconies: Comparison of RANS and LES. Building and Environment 173, 2020, 106747. 